\title{
O PROTAGONISMO INDÍGENA NA CONSTRUÇÃO DO NOVO CONSTITUCIONALISMO LATINO-AMERICANO: PERCEPÇÕES SOCIOJURÍDICAS E ETNOLÓGICAS DESDE E PARA O BRASIL
}

\section{Evilhane Jum Martins ${ }^{1}$ Jerônimo Siqueira Tybusch ${ }^{2}$}

RESUMO: Objetiva-se analisar o modo de construção de novas percepções sociojurídicas e etnológicas acerca do protagonismo indígena desde e para o Brasil, partindo de experiências próprias do Novo Constitucionalismo Latino-americano. Parte-se do seguinte questionamento: Quais os limites e possibilidades para a construção de novas percepções sociojurídicas e etnológicas acerca do protagonismo indígena desde e para o Brasil, a partir das experiências no Novo Constitucionalismo Latino-americano? A fim de responder, metodologicamente optou-se pela perspectiva sistêmica.. Os procedimentos elegidos foram a pesquisa bibliográfica e documental. A técnica empregada foi a construção de fichamentos e resumos estendidos.

PALAVRAS-CHAVE: Protagonismo indígena; Novo Constitucionalismo Latino-americano; Percepções sociojurídicas e etnológicas; Brasil; Visão Multidisciplinar.

\section{THE INDIGENOUS PROTAGONISM IN THE CONSTRUCTION OF THE NEW LATIN AMERICAN CONSTITUTIONALISM: SOCIO-JURIDICAL AND ETHNOLOGICAL PERCEPTIONS FROM AND TO BRAZIL}

\begin{abstract}
The objective is to analyze the way of constructing new socio-juridical and ethnological perceptions about the indigenous protagonism from and to Brazil, starting from the own experiences of the New Latin American Constitutionalism. It is base don't he following question: What are the limit sand possibilities for the construction of new sociojuridical and ethnological perceptions about indigenous protagonism from and toBrazil, base don experiences in the New Latin American Constitutionalism? In order to answer, methodologically the systemic perspective waschosen. The chosen procedures were the bibliographi caland documentary research. The technique used was the construction of extended abstracts.
\end{abstract}

KEYWORDS: Indigenous protagonism; New Latin American Constitutionalism; Sociojuridical and ethnological perceptions; Brazil; Multidisciplinary Vision.

${ }^{1}$ Doutoranda em Direito pela Universidade Federal do Pará (UFPA), Linha de Pesquisa: Direitos Humanos e Meio Ambiente. Mestre em Direito pela Universidade Federal de Santa Maria (UFSM). Bacharel em Direito pela Universidade da Região da Campanha (URCAMP). Docente do Curso de Direito da Universidade Regional das Missões e do Alto Uruguai - Campus Santiago - RS. Integrante do Grupo de Pesquisa Direitos dos Povos e Comunidades Tradicionais da Universidade Federal do Pará, integrante do Grupo de Pesquisa em Direito da Sociobiodiversidade da Universidade Federal de Santa Maria. E-mail: evilhane.martins@gmail.com

2 Professor Permanente do Programa de Pós-Graduação em Direito da UFSM. Professor Permanente do Programa de Pós-Graduação em Tecnologias Educacionais em Rede da UFSM. Professor do Departamento de Direito da UFSM. Pró-Reitor Adjunto de Graduação da UFSM. Líder do Grupo de Pesquisa em Direito da Sociobiodiversidade (Diretório de Grupos de Pesquisa do CNPq). membro da Diretoria do CONPEDI (Gestão 2017 - 2020). Editor da Revista Direitos Emergentes na Sociedade Global (REDESG). Doutor em Ciências Humanas pela Universidade Federal de Santa Catarina - UFSC. Mestre em Direito Publico pela Universidade do Vale do Rio dos Sinos - UNISINOS. Graduado em Direito pela Universidade de Santa Cruz do Sul - UNISC.

CONPEDI LAW REVIEW | QUITO - EQUADOR | v. 4 | n. 2 | p. 314 - 329 | JUL - DEZ | 2018 


\section{INTRODUÇÃO}

A presente pesquisa trata, sumariamente, acerca do protagonismo indígena na América Latina, representado pelas experiências de Bolívia e Equador que deságua no Novo Constitucionalismo Latino-Americano e, o modo pelo qual tais experiências podem revelar elementos impulsionadores do protagonismo indígena emancipatório no Brasil a partir de reflexões advindas de aportes sociojurídicos e etnológicos próprios. Para tanto, parte-se de sustentações teóricas que evidenciam o modo pelo qual a lógica eurocêntrica predomina na América Latina por meio do processo de colonialidade, sobretudo no que pertine à influência sociojurídica que vem sendo contraposta na contemporaneidade pelo movimento denominado como Novo Constitucionalismo Latino-Americano.

Dessa forma, objetiva-se analisar o modo de construção de novas percepções sociojurídicas e etnológicas acerca do protagonismo indígena desde e para o Brasil, partindo de experiências próprias do Novo Constitucionalismo Latino-americano. Partindo de tal premissa a problemática que conduz a presente pesquisa se perfaz da seguinte forma: Quais os limites e possibilidades para a construção de novas percepções sociojurídicas e etnológicas acerca do protagonismo indígena desde e para o Brasil, a partir das experiências no Novo Constitucionalismo Latino-americano?

A fim de responder o presente questionamento, a metodologia empregada obedece ao trinômio: Teoria de Base/Abordagem, Procedimento e Técnica. Como Teoria de Base e Abordagem optou-se pela perspectiva sistêmica, utilizando-se autores com visão multidisciplinar e conectando ares do saber como Antropologia, Direito e Sociologia. Os procedimentos elegidos foram a pesquisa bibliográfica e documental (em meios físicos e digitais ). A técnica empregada foi a construção de fichamentos e resumos estendidos.

Partindo desse ponto, a pesquisa que aqui se desenvolve está dividida de forma interligada e sistemática em duas seções: inicialmente, analisa-se o protagonismo indígena emancipatório na Bolívia e no Equador e, o Novo Constitucionalismo Latino-americano enquanto decorrência sociojurídica de tal protagonismo; por conseguinte, averiguam-se aportes sociojurídicos e etnológicos para a construção do protagonismo indígena emancipatório no Brasil, partindo das perspectivas exitosas refletidas desde a Bolívia e Equador.

Como resultado, verifica-se que novas conformações do protagonismo indígena vem se perfectibilizando no Brasil, as quais permitem que se inicie a construção de uma criticidade 
de caráter emancipatório que vem confrontar os ditames estatais que sempre direcionaram a vida dos povos indígenas até então. Nesse sentido, a imersão indígena no cenário políticocorresponde ao fortalecimento do protagonismo indígena brasileiro que demonstra iniciativas próprias da construção de uma identidade nacional em favor dos direitos dos povos indígenas.

Tal cenário permite a constatação de que no momento atual, não é possível vislumbrar no Brasil a insurgência de uma virada constitucional, conforme visto em Bolívia e Equador, porém pode-se afirmar que assentam-se as bases para a construção de um protagonismo indígena nacional desde e para o Brasil: levando em conta as especificidades etnológicas próprias da história indígena brasileira. Assim, elementos diferenciados é que constituem as bases do protagonismo indígena brasileiro, mas que devem ser enriquecidos pelas experiências que protagonizam o Novo Constitucionalismo Latino-americano na Bolívia e no Equador.

\section{1 - O NOVO CONSTITUCIONALISMO LATINO-AMERICANO ENQUANTO REFLEXO DO PROTAGONISMO INDIGENA EMANCIPATÓRIO NA BOLÍVIA E EQUADOR}

Em virtudeda unicidade atribuída à ideia de desenvolvimento, o processo colonialidade faz com que os parâmetros eurocêntricos e aqueles provenientes de uma racionalidade puramente econômica - característica própria dos países de primeiro mundo sejam capazes de difundir unicamente uma visão reducionista da ideia de desenvolvimento, desconsiderando a diversidade dos aspectos culturais, socioambientais e políticos, de forma que ser desenvolvido é sinônimo da fruição de condições idênticas àquelas perpretadas no Primeiro Mundo.

\footnotetext{
Assim, nos vemos diante de um desses paradoxos constitutivos do mundo modernocolonial, em que a superação da desigualdade se transforma, na verdade, numa busca para que todos sejam iguais... ao padrão cultural europeu norte ocidental e estadunidense. Pareceria até mesmo absurdo dizer-se que todos tem direito a serem iguais... aos ianomâmis, ou aos habitantes da Mesopotâmia (Al Iraq, em árabe). Entretanto, o aparente absurdo só o é na medida em que a colonização do pensamento nos fez crer que há povos atrasados e adiantados, como se houvesse um relógio que servisse de parâmetro universal. Assim, se confunde a luta contra a injustiça social com uma luta pela igualdade conforme uma visão eurocêntrica, enfim, um padrão cultural que se crê superior e, por isso, passível de ser generalizado. Com isso, contribui-se para que se suprima a diferença, a diversidade, talvez o maior patrimônio que a humanidade tenha (2012, p. 64).
} 
Dessa forma, a imposição de um discurso hegemônico que desconsidera a historicidade e identidade da América Latina em prol da centralização do crescimento econômico e da submissão latino-americana aos países ditos desenvolvidos, gera o destoamento crescente entre as regiões centro - periferia em virtude da imposição de necessidades de origem desenvolvimentistas que nada tem a ver com a realidade e com as primordialidades insertas no cenário latino-americano.

O discurso desenvolvimentista hegemônico possui como foco central asseverar a noção de que, ser desenvolvido é promover ações de quaisquer natureza que promovam a igualdade de condições vivenciadas em países primeiro mundistas ${ }^{3}$.

A grande questão é que o uso de estratégias discursivas que privilegiam a reprodução das condições socioeconômicas, políticas e ambientais presentes em estados primeiro mundistas acabam por asseverar o processo desta nova colonização, através da geração de uma contínua dependência socioeconômica da América Latina em relação aos países ditos desenvolvidos. Nos dizeres de Porto-Gonçalves, desde sempre a modernização de acordo com os parâmetros eurocentristas acaba por difundir a colonização:

\begin{abstract}
Assim, sob os auspícios do Banco Mundial e outros organismos supranacionais, se construirão grandes hidrelétricas em vários cantos do mundo, se abrirão estradas por todo o lado, indústrias se transladarão por regiões que antes as desconheciam, assim como a revolução verde colonizará os espaços agrários na América Latina, na Ásia e na África. Mais uma vez, como desde sempre, a modernização foi colonização. Vivemos, hoje, o paradoxo de jamais ter sido tão vasto e profundo o processo de dominação e devastação da natureza quanto nesses últimos 30-40 anos em que até mesmo uma questão - a ambiental - se constituiu. Talvez não tenha havido, em todo mundo, uma região tão emblemática das contradições dessa globalização do desenvolvimento do que a América Latina e, dentre suas regiões, a Amazônia. Canalizou-se, assim, o profundo sentimento emancipatório que vinha das lutas pela descolonização, contra a miséria e contra a injustiça, e se ofereceu, de novo, como
\end{abstract}

\footnotetext{
${ }^{3}$ Ao discorrer acerca das Epistemologias do Sul, Santos demonstra a diferença crucial entre o Norte e o Sul: definidos assim de acordo com a perspectiva social, não levando em conta tão somente os aspectos geográficos: Desde mi punto de vista, lasEpistemologíadelSursonel reclamo de nuevosprocesos de producción, de valorización de conocimientos válidos, científicos y no científicos, y de nuevas relaciones entre diferentes tipos de conocimiento, a partir de lasprácticas de lasclases y grupos sociales que hansufrido, de manera sistemática, destrucción, opresión y discriminación causadas por el capitalismo, el colonialismo y todas lasnaturalizaciones de ladesigualdadenlas que se handesdoblado; el valor de cambio, lapropiedad individual de latierra, elsacrificio de la madre tierra, el racismo, al sexismo, el individualismo, lo material por encima de lo espiritual y todos losdemásmonocultivos de la mente y de lasociedad -económicos, políticos y culturales- que intentan bloquear laimaginación emancipadora y sacrificar las alternativas. En este sentido, sonun conjunto de epistemologías, no una sola, que parte de esta premisa, y de unSur que no es geográfico, sino metafórico: elSurantiimperial. Es la metáfora delsufrimiento sistemático producido por el capitalismo y el colonialismo, así como por otras formas que se hanapoyadoenellos como, por ejemplo, el patriarcado. Es tambiénelSur que existe enel Norte, lo que antes llamábamoseltercer mundo interior o cuarto mundo: los grupos oprimidos, marginados, de Europa y Norteamérica. También existe un Norte global enelSur; sonlas elites locales que se beneficiandel capitalismo global. Por esohablamos de unSurantiimperial. Es importante que observemos la perspectiva de lasEpistemologíasdelSur desde este punto de partida (SANTOS, 2011, p. 16)
} 
solução, mais do mesmo, isto é, mais desenvolvimento (PORTO-GONÇALVES, 2012, p. 65).

Levando em conta o desenvolvimentismo impregnado nas relações geopolíticas que pairam sob a América Latina, refletir sobre a construção do Novo Constitucionalismo Latinoamericano pressupõe necessariamente que se reflita acerca da historicidade da América Latina: formada por determinantes de ordem geopolítica que são responsáveis pela desterritorialização e desculturação dos povos originariamente latinos ${ }^{4}$. Tais redefinições da trajetória latino-americana, formada por anseios eurocêntricos, é que faz emergir o desejo de resgatar e preservar as identidades e peculiaridades inerentes à América Latina.

Nesse diapasão, o Novo Constitucionalismo Latino-americano pode ser considerado um movimento constitucional que é fruto do protagonismo indígena desde Bolívia e Equador, o qual busca reconfigurar os aportes jurídicos e sociais da América Latina. Os elementos etnológicos norteadores do Novo Constitucionalismo Latino-americano, sugerem que se desconstruam paulatinamente as ideias de submissão e de inferioridade advindas da noção de modernidade, enquanto precursora da colonialidade de acordo com Aníbal Quijano e Immanuel Wallerstein:

La americanidadha sido siempre, permanece como tal hasta hoy, un elemento esencialenlo que entendemos como «modernidad». América fueel «Nuevo Mundo» ,un estandarte y una carga asumida desde la partida. Pero a medida que pasabanlossiglos, elNuevo Mundo se convir tióenelpatrón, enel modelo delenterosistem a mundial. ¿Enquéconsistíaesta «novedad»? Lasnovedadesfueroncuatro, una pegada a laotra: colonialidad, etnicidad, racismo y el concepto de lanovedadmisma (QUIJANO, 2014, p. 583-584).

Frente a tais considerações, as insurgências que refletem o Novo Constitucionalismo Latino-americano, para além de ensejar tal movimento constitucional, demonstram o protagonismo indígena no resgate de seus direitos originários e sua autonomia, ao mesmo tempo que se perfazem como importante movimento de contra poder na contemporaneidade. E isso se afirma tendo em vista que o advento da modernidade, de acordo com as palavras de Aníbal Quijano e Immanuel Wallerstein referidas anteriormente, originaram o processo de

\footnotetext{
${ }^{4}$ Nessa mirada, as Américas não foram incorporadas dentro de uma já existente economia mundial capitalista; pelo contrário, não haveria uma economia capitalista mundial sem a existência das Américas (Quijano; Wallerstein, 1992). Quijano (2005) argumenta que esse processo começou com uma colonização interna de povos com identidades diferentes, mas que habitavam os mesmos territórios e foram convertidos em espaços de dominação interna. Esse fenômeno se desdobrou com a colonização imperial ou externa de povos que não só tinham identidades diferentes, como habitavam em territórios para além do espaço de dominação interna dos
} colonizadores (ASSIS, 2014, p. 613). 
integração global então vigente, denominado como globalização, mas que de acordo com o pensamento de Milton Santos revela-se como um verdadeiro globalitarismo: enquanto oconjunto de diversas formas totalitárias de imposição de pensamentos e práticas em favor do capital $^{5}$.

De acordo com tais premissas, Poliene Bicalho refere em sua tese de doutorado que Boaventura de Sousa Santos, por ocasião de sua participação no Fórum Social Mundial em 2002, assemelha o que o autor denomina como cidadania planetária à ideia de um falso universalismo $\left(2010\right.$, p. 234) ${ }^{6}$. A cidadania planetária, citada por Boaventura de Sousa Santos, diz respeito à reprodução em âmbito nacional da política neoliberal implementada no cenário global, identificando-se com a noção de globalização. Já o falso universalismo reflete a ideia inserta na noção de globalitarismo, enquanto modelo que prevê o privilégio de grupos hegemônicos ligados ao capital e sua sobreposição aos direitos das coletividades:

\begin{abstract}
Falso universalismo porque é o Estado capitalista que cada vez mais representa os interesses do mercado e os direitos do empresariado nacional e mundial, e que também se impõe negativamente diante dos direitos das minorias e de diversos grupos étnicos, no geral caracterizados pela diferença cultural em relação ao grupo dominante - a que alguns antropólogos chamam de "brancos" - , e não pela "ideia" que se quer impor, por parte do Estado-Nação, de uma cultura homogênea e uma; mesmo que esta unidade seja resultado de um caldo de culturas formado basicamente pelas etnias indígenas, africanas e europeias (BICALHO, 2010, p. 234).
\end{abstract}

A questão é que a tentativa de homogeneização promovida pelo processo globalitário então vigente se entrelaça com a formação de uma sociedade em rede que, para além de fortalecer a lógica de mercado, acaba por integrar culturas locais e fortalecer pensamentos e ações que deságuam em movimentos contra-hegemônicos. No caso do protagonismo

\footnotetext{
${ }^{5}$ São, todas essas, condições para a difusão de um pensamento e de uma prática totalitárias. Esses totalitarismos se dão na esfera do trabalho como, por exemplo, num mundo agrícola modernizado onde os atores subalternizados convivem, como num exército, submetidos a uma disciplina militar. O totalitarismo não é, porém, limitado à esfera do trabalho, escorrendo para a esfera política e das relações interpessoais e invadindo o próprio mundo da pesquisa e do ensino universitários, mediante um cerco às ideias cada vez menos dissimulado. Cabe-nos, mesmo, indagar diante dessas novas realidades sobre a pertinência da presente utilização de concepções já ultrapassadas de democracia, opinião pública, cidadania, conceitos que necessitam urgente revisão, sobretudo nos lugares onde essas categorias nunca foram claramente definidas nem totalmente exercitadas (SANTOS, 2001, p. 27).

${ }^{6} 4$ Assim, nos vemos diante de um desses paradoxos constitutivos do mundo moderno-colonial, em que a superação da desigualdade se transforma, na verdade, numa busca para que todos sejam iguais... ao padrão cultural europeu norte ocidental e estadunidense. Pareceria até mesmo absurdo dizer-se que todos tem direito a serem iguais... aos ianomâmis, ou aos habitantes da Mesopotâmia (Al Iraq, em árabe). Entretanto, o aparente absurdo só o é na medida em que a colonização do pensamento nos fez crer que há povos atrasados e adiantados, como se houvesse um relógio que servisse de parâmetro universal. Assim, se confunde a luta contra a injustiça social com uma luta pela igualdade conforme uma visão eurocêntrica, enfim, um padrão cultural que se crê superior e, por isso, passível de ser generalizado. Com isso, contribui-se para que se suprima a diferença, a diversidade, talvez o maior patrimônio que a humanidade tenha (PORTO-GONÇALVES, 2012, p. 64).
} 
indígena, sua imersão em espaços antes inimagináveis é fator que utiliza o processoglobalitário como ferramenta para que suas vozes sejam ouvidas e para que sejam capazes de integrar culturas locais frente à desintegração global ${ }^{7}$.

É nesse contexto que o êxito do Novo Constitucionalismo Latino-americano se perfaz. Tal movimento constitucional, vislumbrado claramente nas constituições de Bolívia (2009) e Equador (2008), dispõe sobre a necessidade de se romper com a lógica neoconstitucional que vigorava na América Latina até então, para que se pudessem construir normas constitucionais congruentes com as necessidades, identidades e peculiaridades latinoamericanas $^{8}$.

Nesse ínterim, a primeira Marcha Indigena por elTerritorio y ladignidada qual percorreu $640 \mathrm{~km}$ até a cidade de La Paz inaugurou um novo momento sociojurídico na Bolívia, quiçá na América do Sul, figurando como importante precedente jurídico para a consagração de direitos indígenas, obtendo a ratificação da Convenção 169 da OIT através da Ley de la República $n^{\circ} 1257$ de 11 de julio de 1991, além do reconhecimento constitucional dos direitos indígenas em 1994. A partir daí as lutas indígenas de contra poder protagonizaram uma virada político-jurídica na Bolívia, com a eleição de Evo Morales e o projeto de reconstitución de lanación, nascendo o Estado Plurinacional da Bolívia como palco de uma das mais importantes vertentes do Novo Constitucionalismo Latino-americano (BARRIOS e PINTO, 2007).

No Equador, o protagonismo indígena seguiu o mesmo caminho. $\mathrm{O}$ movimento indígena, com participação ativa da Confederação das Nacionalidades Indígenas do Equador

\footnotetext{
${ }^{7}$ Hall chamou a atenção para a necessidade de se visualizar o "outro" do discurso da globalização, pois ao valorizar o que ele definiu como "nichos de mercado", acabou-se por dar importância também às diferenças locais. Diante disso, percebe-se que "ao invés de pensar o global como "substituindo" o local seria mais acurado pensar numa articulação entre "o global" e o "local" (.BICALHO, 2010, p. 236)

${ }^{8}$ As concepções europeias normativas e sociais que constituíram a colonização da América Latina, apesar de influenciar diretamente nos costumes e regras utilizados na região por séculos, serviram como alicerces basilares para que o povo latino fosse capaz de construir sua própria identidade. No que se refere aos costumes em geral e no que tange ao modo de organização política e social, o continente latino figurou como importador nato das tradições europeias. Porém, essa reprodução da vida europeia efetuou-se em virtude das características impositoras que advieram da colonização, tendo em vista a inexistência de liberdade dos indivíduos que compuseram o povo latino em um primeiro momento. Assim, basta um exame perfunctório na história da colonização da América Latina, para que se constate a incompatibilidade entre o modo de vida imposto e a realidade fática vivenciada na América Latina. Isso ocorreu porque os colonizadores, desde o início da colonização, estabeleceram regras de governo e organização política com características eminentemente europeias, buscando tão somente atender os interesses daqueles que detinham o poder e que nem de longe representavam os interesses da população local. Por consequência, a América Latina passou a ser palco da situação de vulnerabilidade de seus cidadãos, com grande número de pessoas vivenciando condições de extrema pobreza e exclusão social, situação incentivada pela subordinação a que o continente latino se submeteu em relação aos países colonizadores (ARAÚJO e MARTINS, 2015, p. 36-37)
} 
(Conaie), considerada como uma das mais fortes organizações populares da América Latina, reinventou suas manifestações: partindo de ações que tinham por base reivindicações pontuaispara transformarem-se em ações cuja dimensão tomou o cenário nacional. Tal reinvenção foi indispensável para que se pudesse "construir um projeto político alternativo e antagônico ao modelo econômico e à estrutura política até então dominante" ( SOUSA, 2013, p. 284).

Assim, o que se observa é que para além de positivar o regramento constitucional, o Novo Constitucionalismo Latino-americano tem como pressuposto a legitimação constitucional de uma visão holística do meio ambiente, que se capaz de evidenciar a necessidade de reconstrução das relações homem-natureza, evidenciada de forma clara nas constituições da Bolívia e do Equador:

\begin{abstract}
CAPÍTULO SEGUNDO PRINCIPIOS, VALORES Y FINES DEL ESTADO Artículo 8 I. El Estado asume y promueve como principios ético-morales de lasociedad plural: ama qhilla, ama llulla, ama suwa (no seasflojo, no seas mentiroso niseasladrón), suma qamaña (vivirbien), ñandereko (vida armoniosa), tekokavi (vida buena), ivimaraei (tierrasin mal) y qhapajñan (camino o vida noble) (grifo nosso) (BOLÍVIA, 2009). Art. 3.-Sondeberesprimordialesdel Estado: (...) 5. Planificar eldesarrollo nacional, erradicar la pobreza, promover eldesarrollosustentable y laredistribución equitativa de los recursos y la riqueza, para acceder al buenvivir (EQUADOR, 2008).
\end{abstract}

Tendo como base a ideia de "bem viver", assim como a Bolívia, e sendo precursora do giro biocêntrico em que a natureza passa a figurar constitucionalmente como sujeito de direitos, a Constituição do Equador engaja-se na vertente do Novo Constitucionalismo Latinoamericano enquanto reflexo do protagonismo indígena que faz parte, da mesma forma, da realidade boliviana.

Nas palavras de Leonardo Boff, o buenvivir está “inmersoenlagrancomunidad terrenal, que incluyeademás de al ser humano, al aire, el agua, lossuelos, lasmontañas, losárboles y losanimales; es estar en profunda comuniónconlaPachamama (Tierra), conlasenergíasdel Universo, y conDios” (2009).

Certo é que o protagonismo indígena nesses países consiste em fator crucial e determinante para o reconhecimento do contexto continental desde a América Latina e para a América Latina. Ademais, se observa de forma muito clara que o protagonismo indígena vem fomentando continuadamente práticas etnológicas com maior profusão a partir de suas conquistas sociojurídicas na contemporaneidade, de forma que a etnologia indígena vem fazendo parte da realidade de diversos ares do saber, como: Antropologia, Sociologia 
eDireito. Dessa forma, estudos etnológicos caracterizam-se como elementos fundamentais para práticas emancipatórias latino-americanas.

Em virtude de tais argumentos, as experiências latino-americanas quanto o protagonismo indígena norteiam o repensar de tal protagonismo no Brasil: desde aspectos relacionados com a sua diferenciação influenciadora em aspectos sociojurídicos, assim como as conjecturas nacionais que predefiniram a atuação limitada dos movimentos indígenas e as expectativas futuras quanto ao protagonismo indígena brasileiro a partir de percepções etnológicas desde e para o Brasil. Acerca de tais elementos que as próximas linhas dedicar-seão.

\section{2 - APORTES SOCIOJURÍDICOS E ETNOLÓGICOS PARA A CONSTRUÇÃO DO PROTAGONISMO INDIGENA EMANCIPATÓRIO NO BRASIL}

As percepções efetuadas na seção anterior dão conta de demonstrar a relevância do protagonismo indígena, enquanto fator determinante para a resignificação e retomada de aportes norteadores fundamentais para visão desde a América Latina e para a América Latina. Todavia para que perfaça um verdadeiro protagonismo indígena emancipatório em termos latino-americanos é indispensável a inclusão do Brasil neste movimento, enquanto potência sociobiodiversa que exerce relevante papel no que tange à articulações de ressignificações frente à colonialidade, em termos de América Latina.

Sob tais parâmetros, determinados aspectos geopolíticos e etnológicos acerca da construção do movimento indígena no Brasil precisam ser destacados, a fim de que se evidencie características estratégicas que definem a situação atual do protagonismo indígena no Brasil, assim como a razão de sua caminhada distinta quando comparado à Bolívia e Equador. Assim, é imprescindível evidenciar que a construção social brasileira, seja no contexto do colonialismo ou no contexto do processo de colonialidade ${ }^{9}$, sempre esteve adstrita à reprodução do colonialismo interno de forma enraizada e, ainda na contemporaneidade.

\footnotetext{
${ }^{9}$ Para elucidar os desdobramentos sociopolíticos desse processo, Quijano (1997) cunhou o conceito de colonialidade como algo que transcende as particularidades do colonialismo histórico e que não desaparece com a independência ou descolonização. Essa formulação é uma tentativa de explicar a modernidade como um processo intrinsecamente vinculado à experiência colonial. Essa distinção entre colonialidade e colonialismo permite, portanto, explicar a continuidade das formas coloniais de dominação, mesmo após o fim das administrações coloniais, além de demonstrar que essas estruturas de poder e subordinação passaram a ser reproduzidas pelos mecanismos do sistema-mundo capitalista colonial-moderno. Dessa maneira, a noção de colonialidade atrela o processo de colonização das Américas à constituição da economia-mundo capitalista, concebendo ambos como partes integrantes de um mesmo processo histórico iniciado no século XVI (CastroGomez; Gosfroguel, 2007) (ASSIS, 2014, p. 614).
}

CONPEDI LAW REVIEW | QUITO - EQUADOR | v. 4 | n. 2 | p. 314 - 329 | JUL - DEZ | 2018 
Los pueblos, minorías o naciones colonizados por el Estado-naciónsufren condiciones semejantes a las que loscaracterizanenel colonialismo y el neocolonialismo a nivel internacional: habitanenunterritoriosingobiernopropio; se encuentranensituación de desigualdad frente a las elites de las etnias dominantes y de lasclases que lasintegran; suadministración y responsabilidad jurídico-política conciernen a las etnias dominantes, a lasburguesías y oligarquíasdelgobierno central o a los aliados y subordinados delmismo; sus habitantes no participanenlos más altos cargos políticos y militares delgobierno central, salvo encondición de "asimilados"; losderechos de sus habitantes y susituación económica, política, social y cultural son regulados e impuestos por elgobierno central; en general, los colonizados enel interior de un Estado-naciónpertenecen a una "raza" distinta a la que domina enelgobierno nacional, que es considerada "inferior" o, a lo sumo, es convertida enun símbolo "liberador" que forma parte de la demagogia estatal (CASANOVA, 2006, p. 410).

Obviamente que o colonialismo interno não se perfectibiliza tão somente como uma realidade brasileira em termos de América Latina, mas o seu processo continuado e hegemônico demonstra o quão profundo se caracteriza a reprodução do colonialismo interno no Brasil em detrimento de outros países latino-americanos, principalmente quando se trata de protagonismo indígena. E isso se afirma em razão de diversos fatores: seja em função de um menor contingente indígena no Brasil; seja pelo fato de os movimentos indígenas serem localizados; inexistindo uma união nacional efetiva; ou ainda em razão da forma pela qual articulações estatais construíram politicamente discursos que trouxeram para si o prestígio de um suposto protecionismo, que inviabilizou e desconformou quaisquer tentativas de se ter um efetivo protagonismo indígena.

O fato é que o colonialismo interno reproduzido ainda na contemporaneidade é sustentado por tais fatores desconstrutores do protagonismo indígena e, conduzido sumariamente pela figura estatal a partir do século XX circunscrita no Serviço de Proteção ao Índio, cujas ações eram conduzidas desde uma perspectiva desenvolvimentista, de forma a canalizar o colonialismo interno brasileiro com o processo de colonialidade próprio do sistema-mundo:

A criação desse Serviço significou uma profunda mudança no modo de se pensar e tratar a chamada problemática indígena no Brasil, procurando adequá-la à lógica de cidadania burguesa que vinha fortalecendo-se desde o fim da escravidão e à seqüente proclamação da República em 1889. Neste sentido, o surgimento do SPI coroa um movimento iniciado alguns anos antes pela nascente República, nos trabalhos das Comissões Construtoras de Linhas Telegráphicas no Estado de MattoGrosso, que tinha como objetivo unificar o território nacional levando o governo às zonas de sertão, através de um "reconhecimento estratégico, geográfico, econômico e estabelecimento de um esforço de desbravamento e vinculação interna do espaço adscrito pelos limites internacionais estabelecidos, de modo a constituí-lo enquanto território e torná-lo, também, economicamente explorável”. (Lima, 1992: 
162). Somente a partir desta ótica historicizada - o fortalecimento da lógica burguesa, o avanço do grande capital e suas relações de produção, somados à necessidade de integração nacional -, se torna possível entender a criação do SPI e o papel que lhe é atribuído pelas elites brasileiras: concluir, ainda que de forma civilizada e cidadã, a desentrução dos territórios indígenas e a integração de seus povos à economia nacional, conforme Borges (2002, p. 89).

Dessa forma, a posição verticalizada e limitadora por parte do Estado em detrimento dos povos indígenas é que consagra ao longo do tempo um colonialismo interno que inviabiliza qualquer possibilidade de protagonismo indígena. Afora as atrocidades praticadas pelo ente estatal em desfavor dos povos indígenas, denunciadas no Relatório Figueiredo (2013) quando compreendidas entre a criação do Serviço de Proteção ao Índio até meados do período ditatorial e, pelo Relatório da Comissão da Verdade (2014) durante a Ditadura Militar no Brasil, é a preponderância do colonialismo interno brasileiro que impede uma união nacional por parte dos movimentos indígenas e que é favorecida por um menor contingente populacional de povos indígenas em comparação com outros países latino-americanos.

Por meio de um processo de continuidade, o colonialismo interno ${ }^{10}$ brasileiro em detrimento do protagonismo indígena prossegue com a extinção do Serviço de Proteção ao Índio e criação da Fundação Nacional do Índio, criada em meados da década de 1970 com a missão de acelerar o processo de integração nacional e adequar a vida de povos indígenas ao sistema capitalista, em conformidade com a política desenvolvimentista própria do período ditatorial. A questão é que essa política de integração nacional implementada entre os povos indígenas pela Fundação Nacional do Índio fez com que tais povos "entrassem em contato com a lógica da sociedade invasora, proporcionando, contraditoriamente, que estas lideranças, ao se apropriarem desta nova realidade, criassem novas formas de lutas por meio de intensas reelaborações culturais e políticas” (BORGES e BORGES, 2017, p. 06-07). A partir daí a ideia de integração desenvolvimentista assentou as bases para que se construísse a criticidade indígena acerca desse modelo de integração. Portanto, partindo de um período extremamente

\footnotetext{
${ }^{10}$ Nesses caminhos, a falácia da nacionalização dos Estados latino-americanos mascara o eurocentrismo impregnado nas relações sociais, políticas e culturais da sociedade latina, além de perpetuar a relação desigual entre raças e modos de vida por meio da dualidade permanente entre padrão europeu e não europeu e pela reprodução do colonialismo internamente, as sociedades colonizadas sustentam uma estrutura de poder que permite a sedimentação do processo de colonialidade em um círculo vicioso que assevera constantemente o caráter de dependência a que a América Latina se submete. Diante desse quadro, restaram prejudicadas todas as formas de reconhecimento próprio de cultura e identidade latino-americanas em virtude da submissão que atrela a América Latina a ditames pós-coloniais reveladores do surgimento do processo de colonialidade. Por conseguinte, imposições técnico-discursivas fazem com que os parâmetros eurocêntricos e aqueles provenientes de uma racionalidade puramente econômica - característica própria dos países desenvolvidos - sejam capazes de difundir uma visão única e reducionista da ideia de desenvolvimento, privilegiando a economização das relações sociojurídicas e a unicidade do saber (MARTINS, 2018, p. 69)
} 
recente é que as bases para o embate indígena ao colonialismo interno começam a ser construídas.

\begin{abstract}
Esta entrada de milênio vem sendo caracterizada por uma espécie de levante dos povos brasileiros, que se inicia de maneira violenta no ano de 2003, com a homologação da Área Indígena Raposa Serra do Sol em Roraima e pelas ocupações simultâneas de 14 fazendas pelos indígenas Guarani-Kaiowá no Mato Grosso Sul. Em 2004 os Cinta-Larga se tornam notícia nacional por repelirem a ação predadora de milhares de garimpeiros na Área Indígena de Roosevelt em Rondônia, resultando na morte de 29 invasores. Em 2005, diversas lideranças indígenas criam a Articulação dos Povos Indígenas do Brasil (APIB), que, nasce com o papel de representar as demais articulações e organizações indígenas já existentes no País, como a COIAB (Conselho das Organizações Indígenas da Amazônia Brasileira) e a CAPOIB (Conselho de Articulação dos Povos e Organizações Indígenas do Brasil). Estas mobilizações desaguaram no Fórum Social Mundial de 2009, em Belém do Pará, que contou com uma expressiva presença indígena, de aproximadamente 1.200 participantes de diversas etnias regionais e nacionais. Ao que tudo indica a ascensão destes povos ao cenário nacional não será breve, pois, cada vez mais, as comunidades indígenas estão de afirmando enquanto protagonistas políticos (BORGES e BORGES, 2017, p. -6-07).
\end{abstract}

A questão é que novas conformações do protagonismo indígena vem se perfectibilizando no cenário nacional, concedendo margem para a construção de uma criticidade de caráter emancipatório que vem confrontar os ditames estatais que sempre direcionaram a vida dos povos indígenas até então. A imersão indígena no cenário político corresponde ao fortalecimento do protagonismo indígena brasileiro que demonstra iniciativas próprias da construção de uma identidade nacional em favor dos direitos dos povos indígenas. Partindo de tais premissas, segue-se a linha de raciocínio proferida por Theotônio dos Santos:

\begin{abstract}
Si hayenel interior de los países dependientesfuerzasinteresadasenaprovechar esta situación para provocar um cambio de estructura, y si son relativamente fuertes, se creanlas condiciones internas para que, al debilitar-se el centro hegemônico, se produzca uma conyunturafavorable que facilite una ofensiva política de esasfuerzas. La mayor o menor profundidad de esa ofensiva y sus posibilidades de Victoria dependererán, sin embargo, de lacapacidad de lasfuerzas más avanzadas de las sociedades nacionales, de suorganización, de su consciência y de sudisposición de lucha (2011, p. 469).
\end{abstract}

É nesse sentido que o protagonismo indígena no Brasil direciona o seu porvir. Enquanto força contra-hegemônica que vem ocupando espaços de poder de modo diversificado e contrapondo discursos de poder que privilegiam interesses outros, o protagonismo indígena brasileiro se faz presente por meio de manifestações sociais que são propagadas pela sociedade de informação que consequentemente difundem novas formas de pensar e novos saberes até então não legitimados pela ordem hegemônica. No momento atual, não é possível vislumbrar no Brasil a insurgência de uma virada constitucional, conforme 
visto em Bolívia e Equador, porém pode-se afirmar que assentam-se as bases para a construção de um protagonismo indígena nacional desde e para o Brasil: levando em conta as especificidades etnológicas próprias da história indígena brasileira. Assim, elementos diferenciados é que constituem as bases do protagonismo indígena brasileiro, mas que devem ser enriquecidos pelas experiências que protagonizam o Novo Constitucionalismo Latinoamericano na Bolívia e no Equador.

Em vista dos aspectos aqui delineados é que se afirma com entusiasmo que, o pensamento de IdónChivi Vargas quanto ao enfrentamento estrutural frente o colonialismo interno, vem se construindo com o protagonismo indígena brasileiro justamente por abarcar a concepção de que: "La descolonización es precisamente laconstrucción contraria de lo que ocurreenlacolonialidad, no derrumbando paredes ni pateando puertas, sino comprendiendosufuncionamiento, aprendiendo de sus soportes y sometiéndolo a una profunda crítica social" (CHIVI VARGAS, 2010, p. 03).

\section{CONCLUSÃO}

Os argumentos expostos ao longo da presente pesquisa, dão conta de demonstrar que a historicidade indígena brasileira possui contornos peculiares que demonstram quão profundas são as raízes do colonialismo interno e como elas definem a (in)existência de um protagonismo indígena emancipatório.

Outrossim, no que tange às razões e pressupostos que desencadeiam o interesse na reprodução do discurso desenvolvimentista hegemônico, as mesmas se originam diante da permissividade deste grupo seleto utilizar-se das benesses socioeconômicas provindas do capitalismo global através da exploração da América Latina pelos países ditos desenvolvidos à custa da destruição em massa, da sobreposição da pobreza, da desigualdade social e da entrega da biodiversidade, em síntese: à custa da submissão atemporal e da sedimentação de uma nova colonialidade na América Latina, em favor do desfrute momentâneo do resquício de benesses desenvolvimentistas ${ }^{11}$.

\footnotetext{
${ }^{11}$ No processo de objetivação do mundo, o valor de troca desvinculou-se de sua conexão com o real, a economia se desprendeu da condição de materialidade da natureza e da necessidade humana; a generalização dos intercâmbios comerciais se converteu em lei universal, invadindo todos os domínios do ser e os mundos de vida das gentes. Com a invenção da ciência econômica e a institucionalização da economia como regras de convivência universais, teve início um processo de cinco séculos de economização do mundo. Tal processo de expansão da racionalidade econômica chegou a seu ponto de saturação e a seu limite, por efeito de sua extrema vontade de globalizar o mundo devorando todas as coisas e traduzindo-as aos códigos da racionalidade econômica, razão que sustenta a impossibilidade de pensar e agir conforme as condições da natureza, da vida e CONPEDI LAW REVIEW | QUITO - EQUADOR | v. 4 | n. 2 | p. 314 - 329 | JUL - DEZ | 2018
} 
Ao revés, as experiências provindas de Bolívia e Equador demonstram que a articulação nacional de um protagonismo indígena emancipatório geram bases sólidas para o advento de movimentos sociojurídicos que vão para além de assegurar direitos indígenas, asseguram um novo momento constitucional que redefine os paradigmas norteadores de um novo porvir latino-americano.

Assim, levando em conta o questionamento que induziu a presente pesquisa, tem-se que os limites para a construção de novas percepções sociojurídicas e etnológicas acerca do protagonismo indígena desde e para o Brasil, a partir das experiências no Novo Constitucionalismo Latino-americano, são consubstanciados na política desenvolvimentista estatal imposta de maneira verticalizada, bem como a aquisciência com os ditames do sistema-mundo que conformam o processo de colonialidade.

Já as possibilidades que engendram caminhos para o enfrentamento de tais limites, consubstanciam-se, sobretudo em virtude da imersão indígena no cenário político e o fortalecimento do protagonismo indígena brasileiro que demonstra iniciativas próprias da construção de uma identidade nacional em favor dos direitos dos povos indígenas. A construção de uma identidade nacional indígena acarreta o enfrentamento crítico às bases sociojurídicas de caráter eurocêntrico que são impostas, de forma que o protagonismo indígena decorrente ganha contornos emancipatórios: promovendo uma criticidade social capaz de assentar as bases para o processo de descolonização.

\section{REFERÊNCIAS}

ARAÚJO, Marigley Leite de. MARTINS, Evilhane Jum. O novo constitucionalismo latinoamericano e sua correlação com as modificações fáticas e estruturais do Direito Constitucional de Família. In: Direito e Interação na América Latina. Org.: DEL'OLMO, Florisbal de Souza. BEDIN, Gilmar Antonio. ARAÚJO, Marigley Leite de. Vol. 2. Campinas, Millennium: 2015.

ASSIS, Wendell Fischer Teixeira. Do colonialismo a colonialidade: expropriação territorial na periferia do capitalismo. Disponível em: http://www.scielo.br/pdf/ccrh/v27n72/11.pdf Acesso em 24 de abril de 2017.

BICALHO, Poliene Soares dos Santos. Protagonismo indígena no Brasil: movimento, cidadania e direitos (1970-2009). 2010. Tese, -Universidade de Brasília, Brasília, 2010.

da cultura. Esse processo econômico não pode absorver; mas, além disso, através de sua crença fundamentalista e totalitária, se encrava no mundo destruindo o ser das coisas - a natureza, a cultura, o homem - para reconvertelas a sua forma unitária e universal (LEFF, 2006,p. 143-144). 
BOFF, Leonardo. El buenvivir. Disponível em: www.equiposdocentesal.com/decaraalmundo/.../Boff.doc - Acesso em 10 de maio de 2017.

BOLÍVIA, Constituición Politica del Estado. Disponível em: http://www.transparencialegislativa.org/wpcontent/uploads/2013/04/Constitucio\%CC\%81nBolivia.pdf - Acesso em 10 de maio de 2017.

BORGES, Liliam Faria Porto. BORGES, Paulo Humberto Porto. TekohaJevy Guarani: Povos indígenas latino-americanos e protagonismo político no Brasil. Disponível em: http://projetos.unioeste.br/projetos/cidadania/images/stories/POVOS_INDIGENAS.pdf Acesso em 20 de junho de 2017.

BRASIL. Relatório Figueiredo: documento na íntegra. 2013. "Síntese”. Disponível em: http://racismoambiental.net.br/2013/06/02/relatorio-figueiredo-documento-naintegra-7milpaginas-pdf-pode-agora-ser-baixado/. - Acesso em 10 de maio de 2017.

BRASIL. Comissão Nacional da Verdade (CNV). 2014. “ Texto 5 - Violações de direitos humanos dos povos indígenas” In: Relatório da Comissão Nacional da Verdade. V. II Brasília, p. 203-262. Disponível em:

http://www.cnv.gov.br/images/pdf/relatorio/volume_2_digital.pdf. - Acesso em 10 de maio de 2017.

CASANOVA, Pablo Gonzalez. Colonialismo interno: uma redefinición. Buenos Aires: CLACSO, 2006.

CHIVI VARGAS, Idón M. Nueva constitución y desarrollo normativo. Agencia latino americana de información América enmovimiento. Disponível em: . Acesso em 22 de abril de 2017.

ECUADOR, Constituición del. Disponível em:

http://www.asambleanacional.gov.ec/documentos/constitucion_de_bolsillo.pdf - Acesso em 10 de maio de 2017.

KOK, Glória. O protagonismo indígena na fronteira amazônica. In: Revista Estudos Avançados, Vol. 23, N. 67, 2009.

LEFF, Enrique. Racionalidade ambiental: a reapropriação social da natureza. Trad. Luis Carlos Cabral. Rio de Janeiro: Civilização Brasileira, 2006.

MARTÍNEZ DALMAU, Rúben; VICIANO PASTOR, Roberto. Aspectos generalesdelnuevo constitucionalismo latino-americano. In: El nuevo constitucionalismo en América Latina: memorias delencuentro internacional elnuevo constitucionalismo: desafíos e retos para elsiglo XXI. Corte Constitucional delEcuador, Quito, 2010.

MARTINS, Evilhane Jum. A encruzilhada sul-americana na economia dos agrotóxicos: o cenário geopolítico ambiental e as implicações no tratamento jurídico e ecológico. Ijuí: Unijuí, 2018. 
PIMENTA, José. SMILJANIC, Maria Inês.Etnologia Indígena e Indigenismo: novos desafios teóricos e empíricos. Brasília: Positiva, 2012.

PORTO-GONÇALVES, Carlos Walter. A globalização da natureza e a natureza da globalização. 3 ed. Rio de Janeiro: Civilização Brasileira, 2012.

QUIJANO, Aníbal. WALLERSTEIN, Immanuel. La americanidad como concepto, o América enel moderno sistema mundial. In América: 1492-1992. Trayectorias históricas y elementos deldesarrollo. Vol. XLIV, N. 04. Catalunya: UNESCO, 1992.

SANTOS, Boaventura de Sousa. Introducción: lasepistemologíasdelSur in CIDOB (org.), Formas-Otras. Saber, nombrar, narrar, hacer. Barcelona: CIDOB Ediciones, 2011.

, Milton. Por uma outra globalização: do pensamento único à consciência universal. Rio de Janeiro: Record, 2001.

Theotonio dos. Imperialismo y dependencia. 5 ed. Caracas: Fundación Biblioteca Ayacucho, 2011.

SOUSA, Adilson Amorim de. Da "invisibilidade" ao protagonismo: a insurgência do movimento indígena no Equador na década de 1990. In:Politeia: História e Sociedade. Vol. 13, N. 02, 2013. 